\title{
BMJ Open Quality Applying the principles of health technology assessments to intubation boxes for patients with COVID-19
}

\author{
Ekta Khemani, ${ }^{1,2}$ Marianita Lampitoc, ${ }^{3}$ Donald Duvall ${ }^{3}$
}

To cite: Khemani E, Lampitoc M, Duvall D. Applying the principles of health technology assessments to intubation boxes for patients with COVID-19. BMJ Open Quality 2020;9:e001010. doi:10.1136/ bmjoq-2020-001010

Received 5 May 2020 Revised 19 July 2020 Accepted 10 August 2020
Check for updates

(C) Author(s) (or their employer(s)) 2020. Re-use permitted under CC BY-NC. No commercial re-use. See rights and permissions. Published by BMJ.

${ }^{1}$ Department of Anesthesia, McMaster University Faculty of Health Sciences, Hamilton, Ontario, Canada

${ }^{2}$ Department of Anesthesia, Niagara Health System, Saint Catharines, Ontario, Canada ${ }^{3}$ Infection Control and Prevention, Niagara Health System, Saint Catharines, Ontario, Canada

Correspondence to Dr Ekta Khemani; ekta.khemani@niagarahealth. on.ca

\section{INTRODUCTION}

While global efforts are underway to reduce transmission of COVID-19 infection with a shortage of personal protective equipment (PPE), intubation boxes have become a popular new equipment for airway management. ${ }^{1}$ Intubation boxes are essentially barrier enclosures composed of transparent components meant to contain the droplet and aerosols during intubation and prevent them from being dispersed to the environment and healthcare worker (HCW). ${ }^{1}$

Preliminary reports have shown intubation boxes to be effective in reducing droplets, more than aerosol exposure, to the HCW during laryngoscopy. ${ }^{1-3}$ Consequently, these intubation boxes are being mass produced and implemented in both academic and community hospitals worldwide.

With the introduction of new equipment, such as intubation boxes, safety cannot be overemphasised. As Mytton et al discuss, new technology can be a sensitive process with the potential for unforeseen dangers. ${ }^{4}$ Before new devices are introduced into a hospital, they undergo a series of stages including research and development, clinical trials, simulation, and finally, a formal review certifying that it is safe to be used. ${ }^{4-6}$ Ideally, new devices, such as intubation boxes, would undergo a formal health technology assessment (HTA) which is a systematic and robust evaluation of technology. ${ }^{7-10}$

Central to the HTA that is typically done when a medical device is introduced is understanding the implementation (how should we apply it here?), appropriateness (can we apply it safely?), effectiveness (is it safe under real world conditions?), efficacy (is it safe under experimental conditions?) and performance (are there safety concerns?). ${ }^{28-10}$

In the emergency pandemic situation, traditional means to evaluate new equipment such as intubation boxes may not be timely or feasible. However, the safety concerns of introducing new equipment should also not be disregarded. As such, rather than conducting a study on intubation boxes, we developed an evidence-based approach to evaluating the safety of intubation boxes using the components of a formal HTA.

\section{Multidisciplinary evaluation}

Prior to mass introduction of intubation boxes, involvement of key stakeholders must be solicited. A multidisciplinary team including infection control and prevention (IPAC) representatives, nursing, respiratory therapists, anaesthesiologists and engineers are instrumental in evaluating new intubation boxes. ${ }^{258}$

Members from the IPAC department can provide critical feedback for safely using and removing intubation boxes. Studies evaluating infection processes post-severe acute respiratory syndrome emphasised that the time when most errors occurred, and thus most potential for contamination, is in the doffing of PPE. ${ }^{6}$ While preliminary studies discussed how to place an intubation box for laryngoscopy, to our knowledge, there is little evidence on how to safely remove these boxes. Potential contamination at removal of the intubation box is of great concern, and guidance from members of the IPAC department is essential.

Clinical engineers are specialised in implementing technology and are key in understanding environmental infection processes. ${ }^{4}$ For example, clinical engineers can provide information on air exchanges required to simulate a negative pressure environment, and thus reduce aerosolisation. This skill set is valuable in evaluating intubation boxes, as studies have shown that intubation boxes may reduce droplet contamination on the HCW but not necessarily aerosols. ${ }^{1}$

It is also important to recognise the dynamic nature of airway management when implementing devices. Insights from frontline workers, such as anaesthesiologists, respiratory therapists and nurses, are critical 
in understanding potential sources of error when using an intubation box, especially during emergencies. ${ }^{3}$ They have first-hand knowledge specific to airway management and their input cannot be overemphasised.

\section{Simulation}

Simulation affords HCWs the opportunity to practice using intubation boxes in a low-risk environment, and evaluate if the proposed new device is effective and safe. ${ }^{289}$ A study by Begley et al used simulation to test intubation boxes and found the time to intubate with them was significantly higher than intubating without them, potentially leading to hypoxia in the patient with COVID-19. ${ }^{2}$ Moreover, by using intubation boxes, there were breaches in PPE, raising safety concerns for the HCWs. ${ }^{2}$ The authors stressed through simulations, they learnt intubation boxes served as an adjunct rather than a replacement for PPE. ${ }^{2}$ Therefore, simulation is a useful tool in assessing a new device in real time for safety and effectiveness.

\section{Pilot study}

Following simulations, a pilot study is a critical component in evaluating an intubation box. ${ }^{2} 89$ Pilot studies can identify potential problem areas and safety concerns in the clinical setting that may have been missed during the initial stages of planning. Despite extensive planning, literature demonstrates pilot studies usually highlight issues that have not been considered. ${ }^{89}$

Piloting intubation boxes will allow for a greater sample size in evaluating new medical devices. It will also account for testing the intubation box with a diverse population (eg, obese patients, frail patients, etc.). A recent study trialled an intubation box in their anaesthetic and critical care units. ${ }^{3}$ By conducting a pilot study, the authors were able to make appropriate modifications to their intubation box. ${ }^{3}$ This further demonstrates the value of pilot studies as part of an HTA.

\section{Surveillance}

Evaluating the safety of a new medical device is important, as it may capture the potential harm of using the device. $^{2} 89$ Reporting concerns with the intubation boxes must be a user-friendly process in order to truly capture incidents. The data collected from the reporting processes needs to be analysed and addressed in a timely fashion and is clinically meaningful to the HCW. ${ }^{289}$

\section{SUMIMARY}

Intubation boxes are a new medical device that can potentially prevent transmission of COVID-19 to HCWs.
Intubation boxes should not be used as a replacement for PPE, but rather an added device to reduce harm and promote safety for HCWs. ${ }^{23}$ In the absence of large clinical trials or a formal HTA, we propose an evidence-based approach for evaluating intubation boxes. Through involvement of stakeholders, simulation, pilot studies and surveillance, the risk of harm from a new medical device can potentially be mitigated. The potential of a new device causing more harm with inadequate evaluation may override the benefit of introducing it. That is not to say that intubation boxes should not be used, but a methodological approach should be taken prior to mass implementation by HCWs.

Contributors EK is the main author involved in development and writing of the paper. ML and DD also collaborated in the development and writing of the paper.

Funding The authors have not declared a specific grant for this research from any funding agency in the public, commercial or not-for-profit sectors.

Competing interests None declared.

Patient and public involvement Patients and/or the public were not involved in the design, or conduct, or reporting, or dissemination plans of this research.

Patient consent for publication Not required.

Provenance and peer review Not commissioned; externally peer reviewed.

Data availability statement There is no data in this work.

Open access This is an open access article distributed in accordance with the Creative Commons Attribution Non Commercial (CC BY-NC 4.0) license, which permits others to distribute, remix, adapt, build upon this work non-commercially, and license their derivative works on different terms, provided the original work is properly cited, appropriate credit is given, any changes made indicated, and the use is non-commercial. See: http://creativecommons.org/licenses/by-nc/4.0/.

\section{REFERENCES}

1 Cannelli R, Connor CW, Gonzalez M, et al. Barrier enclosure during endotracheal intubation. NEJM 2020.

2 Begley JL, Lavery KE, Nickson CP, et al. The aerosol box for intubation in coronavirus disease 2019 patients: an in-situ simulation crossover study. Anaesthesia 2020;75:1014-21.

3 Malik JS, Jenner C, Ward PA. Maximising application of the aerosol box in protecting healthcare workers during the COVID-19 pandemic. Anaesthesia 2020;75:974-5.

4 Mytton OT, Velazquez A, Banken R, et al. Introducing new technology safely. Qual Saf Health Care 2010;19:i9-14.

5 World Health Organization. Sixtieth World Health AssemblyWHA60.29 health technologies.

6 Peng PWH, Wong DT, Bevan D, et al. Infection control and anesthesia: lessons learned from the Toronto SARS outbreak. Can J Anaesth 2003;50:989-97.

7 Manuele FA. Acceptable risk. In: On the practice of safety. 3rd edn. London, UK: Wiley-IEEE, 2003: 272-86.

8 World Health Organization. Medical device regulation-global overview and guiding principles. Geneva: WHO, 2003.

9 Banta D. What is technology assessment? Int $J$ Technol Assess Health Care 2009;25:7-9.

10 Velasco M, Perleth M, Drummond M, et al. Best practice in undertaking and reporting health technology assessments. Working group 4 report. Int J Technol Assess Health Care 2002;18:361-422. 